Cartas al Director

\title{
HER-2-neu: ¿posible diana del carcinoma vesical?
}

\section{Sr. Director:}

El cáncer de vejiga urinaria es el tumor urotelial maligno más frecuente. Es el quinto tumor más frecuente en varones y el octavo en mujeres. Esta incidencia no guarda correlación con la mortalidad ocupando un noveno puesto entre las causas de mortalidad por cáncer. Esto es debido a la mejora en técnicas diagnósticas detectándose en estadios más tempranos, presentando menor potencial invasor y mejor pronóstico. Esto unido a los avances en el tratamiento ha provocado una detección temprana y un tratamiento precoz. A pesar de estos avances, no podemos decir lo mismo en cuanto al cáncer de vejiga metastásico donde no ha habido grandes cambios. La supervivencia mediana sin tratamiento no supera los 3-5 meses, duración que depende entre otros factores de la localización metastásica, variando de modo considerable si la afectación es ganglionar o visceral. Con la administración de tratamiento quimioterápico se pueden alcanzar supervivencias medianas de hasta 12-15 meses.

Existen varios fármacos con actividad antineoplásica utilizados en el carcinoma vesical, siendo considerados los más activos el cisplatino (CDDP) y el metotrexate, sin olvidar otros fármacos: vinblastina, paclitaxel, docetaxel o la gemcitabina. Una vez se demostró que el empleo de un fármaco en comparación con el mejor tratamiento de soporte mejoraba la supervivencia y aumentaba la calidad de vida, el siguiente paso fue demostrar que el empleo de varios fármacos era superior a la monoterapia. Comentar en este punto la combinación desarrollada en los años 80 por el MSKCC (Memorial SloanKettering Cancer Center), que utilizó una poliquimioterapia basada en el empleo de los agentes más activos: M-VAC (metotrexate, vinblastina, adriami- cina y cisplatino). El estudio que sacaron a la luz tenía un tamaño muestral de 121 pacientes, evaluables con enfermedad ganglionar regional (N1) o metastásica (M1). Con la administración de dicho esquema observaron un $72 \%$ de respuestas globales, correspondiendo el $36 \%$ a respuestas completas. La mediana de seguimiento fue de seis años y observaron una supervivencia mediana de 32,9 meses en los pacientes con afectación ganglionar y una supervivencia mediana de 12 meses en los pacientes con afectación metastásica. Posteriormente se comparó este esquema con CDDP y CISCA (cisplatino, ciclofosfamida y doxorrubicina). Loehrer y Logothetis ${ }^{1,2}$ realizan estudios confirmando un aumento en la supervivencia y en las respuestas para el tratamiento combinado para el esquema M-VAC. A raíz de dichos trabajos fue considerada estándar la combinación M-VAC. Ésta fue la tendencia observada hasta que se observó la elevada actividad de un nuevo fármaco, la gemcitabina (GMZ), fácil de administrar y con efectos adversos admisibles por lo que se estudió combinado con el cisplatino. Von der Maase, Kaufman y Moore ${ }^{3-5}$ estudiaron la combinación CDDP-GMZ, reportando un aumento en el número de respuestas globales (y también completas), además de aumentar la mediana de supervivencia (no significativo), además de menor toxicidad. Desde estos últimos trabajos apenas ha habido avances en el campo, por eso parece conveniente estudiar nuevas vías de actuación.

HER-2 pertenece a la familia de receptores del factor de crecimiento HER de trirosincinasas, mediadores importantes del crecimiento, diferenciación, angiogénesis y supervivencia celular. Es un protooncogen situado en el cromosoma 17 y codifica la proteína transmembrana HER-2/neu. El receptor se localiza en la membrana celular y se constitu- 
ye por un dominio extracelular (unión al ligando), un dominio transmembrana y un dominio intracelular (actividad tirosin-quinasa). HER-2 se comporta como un monómero pero cuando se une a un ligando se dimeriza para la transmisión de señales intracelulares. Se forma un heterodímero de alta señal y potencia mitógena. Estudios preclínicos y clínicos indican que la amplificación del gen HER-2 y la sobreexpresión del receptor tienen un papel crítico en la transformación y génesis tumoral. A mediados de los años 90 surgen diversos estudios en los que se analiza la expresión de HER-2/neu en cáncer de vejiga y su significado. Imai y cols ${ }^{6}$ observan que el $43 \%$ de los tumores transicionales de vejiga sobreexpresaban dicho receptor, y estos tumores tenían una recurrencia significativamente mayor que aquellos que no la sobreexpresaban. Esto fue corroborado por otros autores, como Underwood y cols ${ }^{7}$, que analizaron la sobreexpresión en tumores de vejiga recidivados, observando una fuerte asociación entre sobreexpresión, recurrencia y progresión de la enfermedad. En base a estos trabajos, parece que el rol del HER-2/neu puede constituir un factor pronóstico en la historia natural del tumor. Mellon y cols ${ }^{8}$ estudiaron la sobreexpresión del c-erbB-2 en cancer de vejiga de células transicionales, detectando dicha sobreexpresión en el $21 \%$ de los tumores, pero no observaron como los anteriores autores un aumento de recurrencias en dichos tumores. Otros autores, Lonn y cols ${ }^{9}$, Miyamoto y cols ${ }^{10}$ observaron la misma relación entre sobreexpresión de HER-2/neu y el aumento del riesgo de recurrencia. En estos, dicha sobreexpresión se encontró en el $23 \%$ de los tumores y en el $32 \%$ respectivamente. Otros autores que observan asociación entre dicho gen y la probabilidad de progresión son Kim y cols ${ }^{12}$. Dado estos hallazgos, el siguiente paso natural era estudiar dicha amplificación en tumores avanzados. Jimenez y $\operatorname{cols}^{11}$ analizaron la sobreexpresión en carcinoma de vejiga invasivo y avanzado, así como metastásico. Encontraron sobreexpresión entre el $28 \%$ y el $53 \%$ de los casos dependiendo de si era el tumor primario o metástasis a distancia. Después de analizar la supervivencia llegaron a la conclusión de que dicha amplificación no predecía la supervivencia, aunque puntualizaban que era necesario un estudio de HER2-neu en las metástasis a distancia dado el alto porcentaje de expresión. Un trabajo clave fue el publicado por Wester y cols ${ }^{13}$, en el que ya apuntaron a
HER-2 como una posible diana para la terapéutica del cáncer de vejiga metastásico. Encuentran sobreexpresión en el $81 \%$ de los tumores primarios, y en el $67 \%$ de las metástasis, sugiriendo que la terapia dirigida contra HER-2 neu es una modalidad que se debería estudiar, ya sea como tratamiento complementario o como tratamiento alternativo.

Kruger y cols ${ }^{14}$ observaron amplificaciones en un $41 \%$ de casos, más en tumores de alto grado y con una menor supervivencia (Kaplan-Meier) en estos casos. Identificaron dicha amplificación como factor predictivo independiente. Tsai y cols ${ }^{15}$ no encontraron dichos resultados para HER-2 pero sí para EGFR. Cuando ambos mostraban sobreexpresión había una asociación con afectación linfática, un peor pronóstico y eran más resistentes a tratamientos basados en platino. Latif y cols ${ }^{16}$ analizaron el status de HER-2 y de la polisomía 17 en estadios pT1 y pT2 observando amplificación en 76 y $88 \%$ respectivamente, así como una asociación a un peor pronóstico. Simot y cols ${ }^{17}$ analizaron también HER-2 y TOP2A en T2 y T4 y observaron la sobreexpresión en el 14 y el 3,4\%, respectivamente y dicha sobreexpresión se relacionaba con comportamientos más agresivos.

Los últimos estudios publicados confirman lo ya conocido anteriormente, que HER-2-neu se sobreexpresa en el cáncer de vejiga, con una significación estadística para estadios avanzados, así como con una asociación a un peor pronóstico. El aumento de expresión de HER-2-neu se encuentra también en las metástasis del primario vesical llegando a encontrarse incluso en el $65 \%$ de las metástasis analizadas, un porcentaje similar al encontrado en el tumor primario (Bue et al) ${ }^{18}$.

Dada la ausencia de avances en el tratamiento del cáncer de vejiga metastásico, y la evidencia existente acerca de este receptor, una opción interesante sería la elaboración de un ensayo que incluyese un fármaco contra el HER-2-neu (trastuzumab), con tal de mejorar el pronóstico de los pacientes con esta patología.

\section{J. D. Cumplido, I. Blancas, J. A. García-García, N. Cárdenas, P. Iglesias Servicio de Oncología Médica Hospital Clínico Universitario San Cecilio Granada (España)}




\section{Bibliografía}

1. Loehrer PJ, Elson P, Dreicer R et al. Escalated dosages of methotrexate, vinblastine, doxorubicin and cisplatin in advanced urothelial carcinoma: an ECOG trial. J Clin Oncol 1994; 12:483-486.

2. Logothetis CJ, Finn LD, Smith T et al. Escalated MVAC in metastatis transitional cell carcinoma. Proc Am Soc Clin Oncol 1992; 11:202.

3. Von der Maase H, Andersen L, Crino L, Weinknecht S, Dogliotti L. Weekly gemcitabine and cisplatin combination therapy in patients with transitional cell carcinoma of the urothelium. Ann Oncol 1999; 10:1461-1465.

4. Kaufman D, Raghavan D, Carducci M et al. Phase II trial of gemcitabine plus cisplatin in patients with metastatic urothelial cancer. J Clin Oncol 2000; 18: 1921-27.

5. Moore MJ, Whinkist EW, Murray N et al. Gemcitabine plus cisplatin, an active regimen in advanced urothelial cancer. J Clin Oncol 1999; 17:2876-2881.

6. Imai T, Kimura M, Takeda M, Tomita Y. Significance of epidermal growth factor receptor and c-erbB-2 protein expression in transitional cell cancer of the upper urinary tract for tumour recurrence at the urinary bladder. Br J Cancer 1995;71:69-72.

7. Underwood M, Bartlett J, Reeves J, Gardiner DS, Scott R, Cooke T. C-erbB2 gene amplification: a molecular marker in recurrent bladder tumors. Cancer Res 1995; 55: 242230.

8. Mellon JK, Lunec J, Wright C, Horne CH, Kelly P, Neal DE. C-erbB-2 in bladder cancer. J Urol 1996;155:321-6.

9. Lonn U, Lonn S, Friberg S, Nilsson B, Silfversward C, Stenkvist B. Prognostic value of amplification of c-erb-
B2 in bladder carcinoma. Clin Cancer Res 1995; 1:1189-94.

10. Miyamoto H, Kubota Y, Noguchi S et al. C-erb-b2 gene amplification as a prognostic marker in human bladder cancer. Urology 2000; 55:679.83.

11. Jimenez RE, Hussain M, Bianco FJ et al. Her-2 overexpression in muscle-invasive urothelial carcinoma of the bladder. Clin Cancer Res 2001; 7:2440-7.

12. Kim YW, Huh SH, Park YK, Yoon TY, Lee SM, Hong $\mathrm{SH}$. Expression of c-erb-B2 and p53 protein in gallbladder carcinoma. Oncol Rep 2001; 8:1127-32.

13. Wester K, Sjostrom A, de la Torre M, Carlsson J, Malmstrom PU. Her-2 a possible target for therapy of metastatic urinary bladder carcinoma. Acta Oncol 2002; 41:282-8.

14. Kruger $\mathrm{S}$, Weitsch $\mathrm{G}$, Buttner $\mathrm{H}$ et al. Her2 overexpression in muscle-invasive urothelial carcinoma of the bladder: prognostic implications. Int J Cancer 2002; 102:514-8.

15. Tsai YS, Tzai TS, Chow NW et al. Prognostic values of p53 and Her-2-neu coexpression in invasive bladder cancer. Urol Int 2003; 71:262-70.

16. Latif Z, Watters AD, Dunn I, Grigor KM, Underwood MA, Bartlett JM. Her-2-neu overexpressionin the development of muscle-invasive transitional cell carcinoma of the bladder. Br J Cancer 2003; 89:1305-9.

17. Simon R, Atefi R, Wagner U et al. Her-2 and TOP2A coamplification in urinary bladder cancer. Int $\mathrm{J}$ Cancer 2003;107:764-72.

18. Bue P, Wester K, Sjostrom A et al. Expression of epidermal growth factor receptor in urinary bladder cancer metastases. Int J Cancer 1998;76:189-93.
Correspondencia:
Dr. J. D. Cumplido Burón
Avda. Dr. Olóriz, 18
E-18012 Granada
davidcumplido@hotmail.com 